\title{
Efficacy of Pterocarpus angolensis crude extracts against Candida krusei, Staphylococcus aureus, Streptococcus agalactiae and Escherichia coli
}

\section{Jones Victor Chipinga ${ }^{1}$, John F. Kamanula ${ }^{2}$, Paul Bisrael Ben Moyo ${ }^{3}$}

1. Malawi Adventist University, Malamulo College of Health Sciences, P.O. Box 55, Makwasa, Malawi.

2. Mzuzu University, P/Bag 201, Luwinga, Mzuzu.

3. DDT College of Medicine, Plot 13139-41, BBS Mall
Date Received: 30-Dec-2017

Revision Received: 08-Jun-2018

Date Accepted: 29-Jun-2018

Correspondence: Jones Victor Chipinga

(chipingaj@mchs.adventist.org)

\section{Background}

\section{Abstract}

The medicinal plants used to treat different ailments in Malawi contain important phytochemicals which have bactericidal and antifungal properties. Pterocarpus angolensis, locally known as mlombwa tree, which is found in many parts of Malawi, is one such a plant and was studied.

Aims

In vitro analysis of the antimicrobial properties of Pterocarpus angolensis crude extracts on Staphylococcus aureus, Escherichia coli, Streptococcus agalactiae, Candida krusei and determination of the phytochemicals there in.

Methods

In this study, different organs of P. angolensis, a medicinal plant which is locally used to treat skin diseases, were qualitatively screened for the presence of phytochemical constituents and quantitatively assayed for the antimicrobial activity to ascertain their pharmaceutical potential. The aqueous, dichloromethane and methanolic extracts of the leaves, stem-bark, fruits and roots of the plant were tested against Escherichia coli, Staphylococcus aureus, Streptococcus agalactiae and Candida krusei by the macro tube dilution method. These pathogens were selected due to their significant contribution to infectious disease burden of most hospitals and also the fact that of late, they have shown signs of resistance to conventional antibiotics.

Results

The study revealed that P. angolensis contained tannins, flavonoids, saponins and terpenoids. All the extracts exhibited some antimicrobial activity against the test organisms. However, the activity of the extracts depended on concentration and microbial species. The minimum inhibition concentration (MIC) values of the extracts ranged from $0.166 \mathrm{~g} / \mathrm{ml} \mathrm{to} 0.01046 \mathrm{~g} / \mathrm{ml} \mathrm{with} \mathrm{the}$ dichloromethane and methanolic extracts exhibiting more activity than the aqueous extracts. The minimum bactericidal concentration and minimum fungicidal concentration (MBC and MFC respectively) values of the extracts ranged from $0.166 \mathrm{~g} / \mathrm{ml}$ to $0.0417 \mathrm{~g} / \mathrm{ml}$. Conclusion

The results obtained indicate that Pterocarpus angolensis has both antibacterial and antifungal properties and could be used for the treatment of Taenia capitis (ring worm) and other ailments. Use of the isolated and purified compounds from P. angolensis could increase the susceptibility of the tested pathogenic microorganisms in this study.

Key words: Efficacy, Crude Extracts, Minimum Bactericidal Concentration (MBC), Minimum Inhibitory Concentration (MIC), Minimum Fungicidal Concentration (MFC), phytochemical.

\section{Introduction}

The consumption of herbal products has considerably increased for the past 30 years. Of the world's population, $80 \%$ depend on herbal medicines for their basic health care ${ }^{1}$. This is because modern hospital treatments are fairly expensive compared to traditional and complimentary medicines which are locally available and cheap ${ }^{2,3}$. Secondly, patients whose disease did not respond to conventional drugs or due to cultural reasons often resort to traditional and complementary medicines ${ }^{2}$. Herbal supplements are effectively deployed to treat the following conditions: asthma, eczema, premenstrual syndrome, rheumatoid arthritis, migraine, menopausal symptoms, chronic fatigue, irritable bowel syndrome, and cancer $^{2}$. Besides this exponential increase in use of herbal products, the World Health Organisation has also recently recorded a substantial increase in treatment failure ${ }^{3}$. This is attributed to poor access to advanced medical facilities, prohibitive cost of synthetic drugs and scarcity of medicines in developing countries, thereby prompting indigenous populations to resort to alternative sources of medication ${ }^{1,}$ ${ }^{4}$. Skyrocketing reports on the problem of drug resistance have compelled scientists to resort to exploit plants as they contain different bioactive compounds, hence many plantderived drugs can be produced from a single plant ${ }^{5}$.

Like in many parts of the world, rural communities in Malawi use medicinal plants for fuel and treating different ailments. For example, the fruit of Pterocarpus angolensis is used to treat Taenia capitis in Ntcheu district, central Malawi. In Malawian local language, Nyanja, Pterocarpus angolensis is called mlombwa or mlombe ${ }^{6}$. This deciduous tree native to tropical Africa is treasured for its effectiveness against a wide range of diseases and it is proving to be effective because of its high concentration of tannins and flavonoids ${ }^{2,7}$. P angolensis was also reported to exhibit anti-inflammatory activity and high inhibitory activity against S. aureus, E.coli and Salmonnella typhimurium ${ }^{7}$. Several authors concur that the tree has healing properties against malaria, bilharzia, piles, corneal ulcers, blackwater fever, asthma, tuberculosis and ringworm, just to 
mention a $\mathrm{few}^{2,6,8}$. Besides using herbal products to treat different conditions, herbal drugs for treatment are prepared as tinctures, poultices, powders and even teas by natives ${ }^{7}$.

Although higher plants contain antibiotics and there are many different medicinal plants that are used to treat different ailments in Malawi, little has been done to establish the efficacy of commonly used medicinal plants against pathogenic bacteria and fungi e.g. evaluation of Malawian Vernonia glabra (Steetz), Vatke leaf and Securidaca longepedunculata (Fresen) root extracts for antimicrobial activities ${ }^{9}$. In quest for alternative treatment modalities, it is of unquestionable significance to establish the efficacy and usefulness of $P$. angolensis used by locals for the treatment of bacterial as well as fungal infections.

This study, therefore, aimed at adding to the pool of existing knowledge by revealing that $P$. angolensis has both antibacterial and antifungal properties. Upon purification and derivation of appropriate concentrations of its active agents, it can eventually be recommendaed for consideration as an alternative topical therapy for Taenia capitis (ringworm) and other ailments.

As a broad objective, thi study aimed to analyse the phytochemicals present in Pterocarpus angolensis and evaluate its effectiveness against selected pathogenic bacteria and fungi. The specific objectives were to (a)establish the phytochemicals that are present in Pterocarpus angolensis, (b) determine the minimum inhibitory concentration (MIC) of Pterocarpus angolensis crude extracts against selected pathogenic bacteria as well as fungi, and (c)calculate the minimum bactericidal concentration/minimum fungicidal concentration (MBC/MFC) of Pterocarpus angolensis crude extracts against selected pathogenic bacteria and fungi.

\section{Methods}

In this experimental laboratory based study, sequential extraction of the stem-bark, leaf, root and fruit of P.angolensis was performed using non-polar, medium-polarity and highpolarity solvents i.e. n-hexane, dichloromethane, methanol and water respectively to maximize extraction of bioactive compounds of different polarities which are potential drug sources ${ }^{3}$. Staphylococcus aureus, Streptococcus agalactiae, Escherichia coli and Candida krusei were then exposed to the different levels of concentration of the extracts to determine Minimum Inhibitory Concentration (MIC), Minimum Bactericidal Concentration (MBC) and Minimum Fungicidal Concentration (MFC) of the crude extracts using standard macro-tube dilution method.

\section{Collection and pretreatment of plant material}

Fresh plant parts (leaves, bark, fruits and roots) were conveniently collected in September-October 2015 from Pterocarpus angolensis trees free of disease along Nkhata-Bay Forest Reserve with the help of the National Herbarium and Botanic Gardens of Malawi (NHBM) plant taxonomist (Mzuzu office) who identified the plant. Herbarium specimens were deposited at the NHBM. Collected plant materials were washed and air-dried at room temperature under shade. Using a grinding machine, mortar and pestle, each organ was ground to a uniform powder, sieved (\#40 $0.420 \mathrm{~mm}$ ) then stored in dark bottles and appropriately labelled with its respective organ name until use. Different parts of the plant were analyzed separately.

\section{Extraction of plant material}

Extraction of the plant material was done sequentially as explained by Kamanula et $\mathrm{a}^{10}$ and Sukhdev Swami Handa ${ }^{11}$. Each powdered plant material (50g) (bark, root, fruit and leaf) was macerated in $300 \mathrm{ml}$ of sterile $\mathrm{n}$-hexane. The contents were then shaken vigorously and left to stand at room temperature for 48 hours with occasional shaking. Using a well cleaned Buchner flask and funnel, the contents were then filtered through a Whatman filter paper no.1 $(7.0 \mathrm{~cm})$ with the aid of a pressure pump. To ensure total extraction, $100 \mathrm{ml}$ of $\mathrm{n}$-hexane was added to the residues and left to stand for 48 hours and then filtered. The n-hexane extracts were combined and dried on the rotary evaporator $\left(50{ }^{\circ} \mathrm{C}\right)$. To the residues, $300 \mathrm{ml}$ of sterile dichloromethane was added. The contents were then shaken vigorously and left to stand at room temperature for 48 hours with occasional shaking. After filtration, the extraction process was repeated with methanol as a solvent. Dried extracts were kept in the refrigerator $\left(4^{\circ} \mathrm{C}\right)$ until needed for efficacy testing. To another $50 \mathrm{~g}$ of each plant material, $300 \mathrm{ml}$ sterile distilled water was added and the mixture was shaken vigorously and left to stand for 48 hours at ambient temperature in the laboratory. The extract was filtered and the filtrate was kept in the refrigerator until when it was used. Water extracts were not dried on the rotary evaporator because it proved difficult to remove all the water by this method.

\section{Preparation of serial dilution of test extracts}

Preparation of serial dilutions was performed using standard operating procedure adopted from University of Maryland as follows: distilled water $(20 \mathrm{ml})$ water was added to $3.32 \mathrm{~g}$ extract for emulsification and reconstitution to give a starting concentration of $0.166 \mathrm{~g} / \mathrm{ml}$. The final two-fold dilutions of extracts were prepared volumetrically in the broth by transferring $2 \mathrm{ml}$ of the solution from the stock extract solution to the first tube. Then, $1 \mathrm{ml}$ from the first tube was pipetted to the second tube containing broth, followed by a third one and continued to make serial dilution until the entire range of 8 dilutions was covered. A panel contained 8 dilutions of an extract and 2 control tubes. One tube was used as a positive growth control (broth plus inoculum), and the other served as a negative control (broth only). A sum of 4 panels of different extracts (leaf, stem-bark, root and fruit) were prepared and tested against each organism. A minimum final volume of $1 \mathrm{ml}$ of each dilution was needed for the test.

\section{Phytochemical screening}

Qualitative analyses were carried out on the roots, bark, fruits and leaves of P. angolensis. Qualitative analyses included identification for the presence or absence of certain classes of compounds such as alkaloids, tannins, terpenoids, saponins, anthraquinones/quinines, flavonoids and anthocyanins, among others. Standard methods described by Harborne ${ }^{12}$, Sofowora ${ }^{13}$ and other authors were used for qualitative analyses. All reagents used were of Analytical Reagent (AR) grade. The experiments were performed in a chemistry laboratory at Mzuzu University, following standard operating procedures.

\section{Preparation of culture media}

Aseptic technique was followed in preparation of culture media. Benches were decontaminated using freshly prepared $0.5 \%$ sodium hypochlorite. The culture media was prepared according to manufacturer's instructions. Media included MacConkey Agar, Blood Agar, Brain Heart Infusion Broth, 
Muller Hinton Agar, Saboroud Dextrose Agar and Mast IDChromagar Candida.

\section{Microorganisms}

Growth inhibitory effects of all fractions of extracts obtained from all parts of P.angolensis were tested against the following microorganisms: Candida krusei, Staphylococcus aureus, Streptococcus agalactiae and Escherichia coli. These were isolated from patient specimens submitted to Malamulo Mission Hospital Laboratory. For confirmation of identification of bacteria and fungi, conventional methods were used including gram-stain, culture and biochemical tests along with control strains of American Type Culture Collection (ATCC) viz. Staphylococcus aureus ATCC 29213, Escherichia coli ATCC 35218, Streptococcus agalactiae ATCC BAA-1138 and Candida krusei ATCC 14243. C.krusei identification was further confirmed using Chrom agar.

These organisms were resistant strains and they were chosen for the important reason of effectively assessing the antimicrobial properties of $P$. angolensis. Inhibition of growth of such resistant strains after exposure to $P$. angolensis, would mean a breakthrough. This would qualify $P$. angolensis to be an alternative source of antimicrobial agents against the tested and other organisms. Therefore, expanding research would ensure to isolate, identify, purify and harvest active ingredients. Proper processing of the harvested active ingredients would then become the basis of the alternative antimicrobial therapy.

Their responses to antibiotic sensitivity testing wereas follows: E. coli was sensitive to ceftriaxone, intermediate to streptomycin but resistant to sulphamethoxazole/ trimethoprim and amoxicillin; $S$. agalactiae was sensitive to penicillin, streptomycin, gentamycin and ampicillin and it was resistant to none of the available drugs; $S$. aureus was sensitive to streptomycin, amoxicillin and ampicillin, and it was resistant to penicillin while C. krusei was sensitive to fluconazole.

\section{Inoculum preparation}

Four to five isolated colonies of each bacterium of same cultural characteristics were picked using an inoculating loop from overnight growth on agar medium (Oxoid, UK), and suspended in sterile saline $(0.89 \%)$. This was agitated on a vortex mixer and the turbidity of suspension matched with that of the $0.5 \mathrm{McF}$ arland standard, by addition of saline or inoculum. The inoculum was conformed to be equivocal to that of $0.5 \mathrm{McF}$ arland spectrophotometrically at $625 \mathrm{~nm}$ through a $1 \mathrm{~cm}$ cell path to give an absorbance of $0.08-0.10$. This approach eliminated the time needed for growing the inoculum in broth ${ }^{14}$.

\section{Determination of antimicrobial activity against selected common pathogenic bacteria and fungi}

Minimum Inhibitory Concentration (MIC), Minimum Bactericidal Concentration (MBC) and Minimum Fungicidal Concentration (MFC) were taken as measurement parameters to quantify the effects of antimicrobial agents. MIC is the lowest concentration of an antimicrobial agent that inhibits growth as determined visually after a standard incubation period of $18-24$ hours at $35-37^{\circ} \mathrm{C}^{14}$. The MBC and MFC is the lowest concentration of the agent that shows no growth after a subculture of all the dilutions that showed no growth in the MIC test.
Results

Table 1: Preliminary phytochemical screening of stem-bark, leaf, fruit and root of Pterocarpus angolensis

\begin{tabular}{|l|l|l|l|l|}
\hline COMPONENTS & STEM-BARK & LEAF & FRUIT & ROOT \\
\hline Flavonoids & - & ++ & - & - \\
\hline Tannins & +++ & +++ & ++ & - \\
\hline Saponins & ++ & - & - & +++ \\
\hline Anthraquinones & - & - & - & - \\
\hline Alkaloids & - & - & - & - \\
\hline Anthocyanins & - & - & - & - \\
\hline Terpenes & - & ++ & - & - \\
/Terpenoids & & & & \\
\hline
\end{tabular}

Key: $+++=$ Appreciable amount,$++=$ Moderate amount,$+=$

Trace amount , - = Completely absent.

Table 1 shows that the stem-bark, leaf and fruit contain the highest concentration of tannins, while saponins are only found in the stem-bark and root. Overall the leaf is the plant part with the highest number of a variety of phytochemicals namely flavonoids, tannins and terpenes.

Table 2: The organoleptic properties of Pangolensis extracts and their extractive values

\begin{tabular}{|c|c|c|c|c|}
\hline $\begin{array}{l}\text { PLANT } \\
\text { PART } \\
\text { USED }\end{array}$ & \begin{tabular}{|l} 
SOLVENT \\
USED \\
FOR \\
EXTRACTION
\end{tabular} & $\begin{array}{l}\text { COLOUR } \\
\text { OF THE } \\
\text { EXTRACTS }\end{array}$ & $\begin{array}{l}\text { TEXTURE } \\
\text { OF THE } \\
\text { EXTRACTS }\end{array}$ & $\begin{array}{l}\text { YIELD } \\
(\%)\end{array}$ \\
\hline Leaf & Methanol & Coffee & Dried powder & 13.76 \\
\hline Root & Methanol & Dark-Tarn & Sticky mass & 8.79 \\
\hline Bark & Methanol & $\begin{array}{l}\text { Reddish - } \\
\text { Brown }\end{array}$ & Dried powder & 16.00 \\
\hline Fruit & Methanol & Coffee & Sticky mass & 19.04 \\
\hline Root & \begin{tabular}{|l|} 
Dichloromethane \\
\end{tabular} & Red & Sticky mass & 3.03 \\
\hline Bark & Dichloromethane & Yellow & Sticky mass & 1.26 \\
\hline Fruit & Dichloromethane & Green & Sticky mass & 1.64 \\
\hline Leaf & Dichloromethane & Green & Sticky mass & 2.37 \\
\hline Root & Water & Brown & Liquid & $\mathrm{N} / \mathrm{A}$ \\
\hline Leaf & Water & Green & Liquid & $\mathrm{N} / \mathrm{A}$ \\
\hline Bark & Water & Brown & Liquid & $\mathrm{N} / \mathrm{A}$ \\
\hline Fruit & Water & Coffee & Liquid & $\mathrm{N} / \mathrm{A}$ \\
\hline
\end{tabular}

The organoleptic properties and extractive values of $P$. angolensis extracts are depicted in table 2. The methanolic extracts yielded the highest percentage of extract of up to $19.04 \%$ and the extracts were characteristicaly either dried powder or a sticky mass with a perculiar colour depending on the plant part used. On the other hand, the medium polarity extracts yielded sticky mass extracts which had colour ranges of yellow, green and brown as per different plant parts used. However, we could not compute the percent yield for aqueous extracts but they all had a liquid texture. 
Table 3: Results of sensitivity testing of S. aureus, S. agalactiae, E.coli and C. krusei to extracts of Pterocarpus angolensis

\begin{tabular}{|c|c|c|c|c|c|c|c|c|c|c|}
\hline ORGAN & $\begin{array}{l}\text { EX T R A C T I N G } \\
\text { SOLVENT }\end{array}$ & CONCENTRATION & S.aureus MIC & S.aureus MBC & $\begin{array}{l}\text { S.agalactiae } \\
\text { MIC }\end{array}$ & $\begin{array}{l}\text { S.agalactiae } \\
\text { MBC }\end{array}$ & $\begin{array}{l}\text { E.coli } \\
\text { MIC }\end{array}$ & $\begin{array}{l}\text { E.coli } \\
M B C\end{array}$ & $\begin{array}{l}\text { C.krusei } \\
\text { MiC }\end{array}$ & $\begin{array}{l}\text { C.kruse } \\
\text { MFC }\end{array}$ \\
\hline Leaf & Water & $0.166 \mathrm{~g} / \mathrm{ml}$ & Resistant & N/A & Resistant & N/A & Resistant & N/A & Sensitive & growth \\
\hline \multirow[t]{3}{*}{ Bark } & Water & $0.166 \mathrm{~g} / \mathrm{ml}$ & Sensitive & growth & Sensitive & growth & Resistant & N/A & Sensitive & growth \\
\hline & & $0.0833 \mathrm{~g} / \mathrm{ml}$ & Resistant & N/A & Sensitive & growth & Resistant & N/A & Resistant & N/A \\
\hline & & $0.04166 \mathrm{~g} / \mathrm{ml}$ & Resistant & N/A & Sensitive & growth & Resistant & N/A & Resistant & $N / A$ \\
\hline Fruit & Water & $0.166 \mathrm{~g} / \mathrm{ml}$ & Resistant & N/A & Resistant & N/A & Resistant & N/A & Sensitive & growth \\
\hline \multirow[t]{8}{*}{ Root } & Water & $0.166 \mathrm{~g} / \mathrm{ml}$ & Resistant & N/A & Sensitive & growth & Resistant & N/A & Sensitive & growth \\
\hline & & $0.0833 \mathrm{~g} / \mathrm{ml}$ & Resistant & N/A & Sensitive & growth & Resistant & N/A & Resistant & N/A \\
\hline & & $0.04166 \mathrm{~g} / \mathrm{ml}$ & Resistant & N/A & Sensitive & growth & Resistant & N/A & Resistant & N/A \\
\hline & & $0.0208 \mathrm{~g} / \mathrm{ml}$ & Resistant & N/A & Sensitive & growth & Resistant & N/A & Resistant & N/A \\
\hline & & $0.01042 \mathrm{~g} / \mathrm{ml}$ & Resistant & N/A & Sensitive & growth & Resistant & N/A & Resistant & N/A \\
\hline & & $0.005208 \mathrm{~g} / \mathrm{ml}$ & Resistant & N/A & Sensitive & growth & Resistant & N/A & Resistant & N/A \\
\hline & & $0.0026 \mathrm{~g} / \mathrm{ml}$ & Resistant & N/A & Sensitive & growth & Resistant & N/A & Resistant & N/A \\
\hline & & $0.0013 \mathrm{~g} / \mathrm{ml}$ & Resistant & N/A & Sensitive & growth & Resistant & N/A & Resistant & N/A \\
\hline \multirow[t]{3}{*}{ Leaf } & Dichloromethane & $0.166 \mathrm{~g} / \mathrm{ml}$ & Resistant & N/A & Sensitive & growth & Resistant & N/A & Sensitive & growth \\
\hline & & $0.0833 \mathrm{~g} / \mathrm{ml}$ & Resistant & N/A & Sensitive & growth & Resistant & N/A & Resistant & N/A \\
\hline & & $0.04166 \mathrm{~g} / \mathrm{ml}$ & Resistant & N/A & Sensitive & growth & Resistant & N/A & Resistant & N/A \\
\hline \multirow[t]{3}{*}{ Bark } & Dichloromethane & $0.166 \mathrm{~g} / \mathrm{ml}$ & Resistant & N/A & Sensitive & no growth & Resistant & N/A & Sensitive & growth \\
\hline & & $0.0833 \mathrm{~g} / \mathrm{ml}$ & Resistant & N/A & Sensitive & growth & Resistant & N/A & Resistant & N/A \\
\hline & & $0.04166 \mathrm{~g} / \mathrm{ml}$ & Resistant & N/A & Sensitive & growth & Resistant & N/A & Resistant & N/A \\
\hline \multirow[t]{3}{*}{ Fruit } & Dichloromethane & $0.166 \mathrm{~g} / \mathrm{ml}$ & Resistant & N/A & Sensitive & no growth & Resistant & N/A & Sensitive & growth \\
\hline & & $0.0833 \mathrm{~g} / \mathrm{ml}$ & Resistant & N/A & Sensitive & no growth & Resistant & N/A & Resistant & N/A \\
\hline & & $0.04166 \mathrm{~g} / \mathrm{ml}$ & Resistant & N/A & Sensitive & growth & Resistant & N/A & Resistant & N/A \\
\hline \multirow[t]{5}{*}{ Root } & Dichloromethane & $0.166 \mathrm{~g} / \mathrm{ml}$ & Sensitive & growth & Sensitive & no growth & Resistant & N/A & Sensitive & no growth \\
\hline & & $0.0833 \mathrm{~g} / \mathrm{ml}$ & Sensitive & growth & Sensitive & no growth & Resistant & N/A & Resistant & N/A \\
\hline & & $0.04166 \mathrm{~g} / \mathrm{ml}$ & Resistant & N/A & Sensitive & no growth & Resistant & N/A & Resistant & N/A \\
\hline & & $0.0208 \mathrm{~g} / \mathrm{ml}$ & Resistant & N/A & Sensitive & growth & Resistant & N/A & Resistant & N/A \\
\hline & & $0.01042 \mathrm{~g} / \mathrm{ml}$ & Resistant & N/A & Sensitive & growth & Resistant & N/A & Resistant & N/A \\
\hline \multirow[t]{4}{*}{ Leaf } & Methanol & $0.166 \mathrm{~g} / \mathrm{ml}$ & Sensitive & no growth & Sensitive & no growth & Resistant & N/A & Sensitive & no growth \\
\hline & & $0.0833 \mathrm{~g} / \mathrm{ml}$ & Sensitive & growth & Sensitive & no growth & Resistant & N/A & Resistant & N/A \\
\hline & & $0.04166 \mathrm{~g} / \mathrm{ml}$ & Resistant & N/A & Sensitive & growth & Resistant & N/A & Resistant & $N / A$ \\
\hline & & $0.0208 \mathrm{~g} / \mathrm{ml}$ & Resistant & N/A & Sensitive & growth & Resistant & N/A & Resistant & N/A \\
\hline \multirow[t]{2}{*}{ Bark } & Methanol & $0.166 \mathrm{~g} / \mathrm{ml}$ & Sensitive & growth & Sensitive & growth & Resistant & N/A & Sensitive & no growth \\
\hline & & $0.0833 \mathrm{~g} / \mathrm{ml}$ & Resistant & N/A & Sensitive & growth & Resistant & N/A & Resistant & N/A \\
\hline \multirow[t]{2}{*}{ Fruit } & Methanol & $0.166 \mathrm{~g} / \mathrm{ml}$ & Sensitive & growth & Sensitive & no growth & Resistant & N/A & Sensitive & no growth \\
\hline & & $0.0833 \mathrm{~g} / \mathrm{ml}$ & Resistant & N/A & Sensitive & growth & Resistant & N/A & Resistant & N/A \\
\hline \multirow[t]{2}{*}{ Root } & Methanol & $0.166 \mathrm{~g} / \mathrm{ml}$ & Sensitive & no growth & Sensitive & no growth & Resistant & N/A & Sensitive & no growth \\
\hline & & $0.0833 \mathrm{~g} / \mathrm{ml}$ & Sensitive & no growth & Sensitive & growth & Resistant & $N / A$ & Resistant & N/A \\
\hline
\end{tabular}

Key:

Sensitive: Indicates that organism was susceptible to effect of extract.

Resistant: Denotes that extract did not show any activity

Growth: Means sensitive culture was not completely eliminated by the extract

No growth: Indicates sensitive culture was completely eliminated by the extract 


\section{Anti-microbial activities}

All the extracts from all portions of the plant involved in this study exhibited some antimicrobial activity against the test organisms. However, the antimicrobial activity of the extracts varied according to plant part used, polarity and concentration as illustrated in table 3 of results. The MIC values of the extracts ranged from $0.166 \mathrm{~g} / \mathrm{ml}$ to 0.01046 $\mathrm{g} / \mathrm{ml}$ with the dichloromethane and methanolic extracts exhibiting more activity than the aqueous extracts. The MBC and MFC values of the extracts ranged from $0.166 \mathrm{~g} / \mathrm{ml}$ to $0.0417 \mathrm{~g} / \mathrm{ml}$. Although, dichloromethane and methanolic extracts showed activity against S.aureus, S.agalactiae and C.krusei, none of them proved effective against E.coli regardless of concentration and plant part used.

\section{Discussion}

The study demonstrated that antimicrobial activity varied with solvents used for extraction. Dichloromethane and methanolic extracts showed most activity compared to water extracts (Table 3). Maximum inhibition was exhibited at a concentration of $0.166 \mathrm{~g} / \mathrm{ml}$ for most extracts against $S$. aureus, $S$. agalactiae and C. krusei. However, minimum inhibition of dichloromethane root extract went as low as $0.01042 \mathrm{~g} /$ $\mathrm{ml}$ for $S$. agalactiae whereas leaf methanolic extracts inhibited the same organism at the least concentration of $0.0208 \mathrm{~g} / \mathrm{ml}$. Samie et al. and Steenkampa et al. documented the activity of $P$. angolensis against $S$. aureus, $S$. pyogenes, E. coli and E. bistolytica while Luseba et al. depicted that $P$. angolensis was rich in phytochemical compounds such as tannins which explains its antibacterial activity ${ }^{7,15,16}$. Therefore the antibacterial and antifungal properties exhibited by the different extracts of P. angolensis in this study may be attributed to the presence of tannins, flavonoids and saponnins detected during phytochemical screening (Table 1).

Dichloromethane extracts exhibited limited activity against $S$. aureus, but were better inhibitors than water extracts because they did not only inhibit some of the test organisms, rather they completely killed some of them, which was not the case with water extracts (Table 3). Although all extracts of $P$. angolensis did not exhibit activity against E. coli in this study (Table 3), Samie et al. and Steenkampa et al. documented the activity of $P$. angolensis against $S$. aureus, $S$. pyogenes, E. coli and E. histolytica ${ }^{15,16}$. Therefore, it is unsafe to conclude that this plant does not contain broad spectrum antimocrobial properties considering that it was only tested against a single strain of wild type gram negative bacteria. This might have had an effect as the organisms used in the previuos studies were mutant species. Furthermore, crude extracts were used in this study, implying that lack of purity and antagonistic effect of other constituents might have reduced the effectiveness of the active compounds in the extracts.

Medicinal and healing properties of plants are closely related to their chemical components which are classified into some major groups like alkaloids, acids, essential oils, steroids, saponins, tannins and many more. Getting these chemicals out into the herbal remedy depends upon the solubility of these compounds in various solvents. Against all the tested bacterial and fungal strains, methanolic and dichloromethane extracts of all the samples showed better antibacterial as well as antifungal activities compared to aqueous extracts (Table 3). However, both rural and urban communities use water as a solvent for most of the herbs used in the treatment of ailments. This study, therefore, provides substantive evidence that would substantiate the use of solvents that enhance more extraction and the best plant parts containing the highest concentration of active compounds for better efficacy in relieving mankind of the burden of disease (Table 1). For example, adding locally brewed ethanol (kachasu) to water that is used for extraction of P. angolensis would probably increase the efficacy of the plant extracts against particular microorganisms.

\section{Limitations of the study}

In this study, we could not compute the percent yield of water extracts (Table 2) due to lack of equipment needed for drying water extracts. Furthermore, sensitivity testing on non-polar extracts extracted using $\mathrm{n}$-hexane proved futile as we could not access dimethyl sulphoxide (DMSO) which is a key solvent that reduces toxicity of extracting solvent against test microorganisms and mediates the non-polar extracts to be miscible with water.

\section{Conclusions, recommendations and future work}

Based on this study, Pterocarpus angolensis crude extracts have great potential as antimicrobial agents against bacteria and fungi. The results obtained indicate that $P$. angolensis has both antibacterial and antifungal properties and could be used for the treatment of ring worm and other ailments. It can, therefore, be used as an alternative source of antibiotics, following further studies. The results obtained in this study suggest that $P$. angolensis could be used in the development of purified and approppriate concentrations which could be used as alternative topical treatment of skin infections caused by bacteria and fungi that could be resistant to conventional antibiotics. Therefore, the antibacterial and antifungal properties shown in this study support the traditional use of the plant used in this study in the treatment of S. aureas, S. agalactiae, E. coli and C. Krusei infections. Because of the broad spectrum antimicrobial properties of the plant extracts, we can infer that other microorganisms could also be susceptible.

A more detailed phytochemical analysis should be conducted in order to determine the bioactive compounds present in $P$. angolensis. Secondly, isolation of the active ingredients should be performed. Thirdly, testing for the efficacy of $P$. angolensis extracts against a large number of other pathogenic microorganisms should be done to give a representative picture of the antimicrobial activity. Finally, sensitivity testing on the non-polar extracts (i.e. those extracted using n-hexane) could be performed using dimethyl sulphoxide (DMSO) to establish their efficacy. These would result in more generalizable results on the antimicrobial activity of P. angolensis. Based on the results in this study, toxicological studies should be conducted on P. angolensis extracts in order to authenticate its safety for use in the treatment of infections. When such scientific data becomes available, P. angolensis can become an alternative to conventional antibiotics to which many microorganisms have become resistant. Since there are several active agents in $P$. angolensis, isolation and purification of these compounds could lead to the development of new synthetic antimicrobial agents, adding to the pool of antimicrobial agents on the market today.

\section{Acknowledgement}

The writing of this manuscript was jointly supported by the Africa Center of Excellence in Public Health and Herbal Medicine (ACEPHEM), College of Medicine, University of Malawi and Consortium for Advanced Research Training 
in Africa, (CARTA). ACEPHEM receives finances through a grant from the Malawi Government from an IDA Credit facility (ACE II) (P151847) Credit number 5802-MW. CARTA is jointly led by the African Population and Health Research Center and the University of the Witwatersrand and funded by the Carnegie Corporation of New York (Grant No--B 8606.R02), Sida (Grant No:54100029), the DELTAS Africa Initiative (Grant No: 107768/Z/15/Z). The DELTAS Africa Initiative is an independent funding scheme of the African Academy of Sciences (AAS)'s Alliance for Accelerating Excellence in Science in Africa (AESA) and supported by the New Partnership for Africa's Development Planning and Coordinating Agency (NEPAD Agency) with funding from the Wellcome Trust (UK) (Grant No: 107768/Z/15/Z) and the UK government. The statements made and views expressed are solely the responsibility of the authors.

\section{References}

1. World Health Organisation. Prevention and containment of antimicrobial resistance. Report of a regional meeting (internet). Chiang Mai, Thailand: 2010 (cited 2016 May 13). Available from: http://www. searo.who.int/entity/antimicrobial_resistance/BCT_Reports_SEAHLM-408.pdf

2. Maroyi A. Traditional use of medicinal plants in south-central Zimbabwe: review and perspectives. J Ethnobiol Ethnomed. 2013; 9:31. doi: 10.1186/1746-4269-9-31

3. Reuters Brand Features. Future Trend of Herbal Medicine Market 2018 Scope at a CAGR of $~ 7.2 \%$ during 2017 to 2023 | Increasing Demand for Safe Therapies (Internet). 2018 (cited 2018 April 7). Available from: https://www.reuters.com/brandfeatures/venturecapital/article?id=32992

4. World Health Organisation. Health effects of particulate matter. Policy implications for countries in eastern Europe, Caucasus and central Asia (internet). 2013. [cited 2015 Aug 5). Available from: http// www.euro. who.int/_data/assets/.../Health-effects-of-particulate-matter-final-Eng. pdf

5. Rana SM, Billah MD, Hossain MS, Saifuddin AKM, AzizulIslam SKM, Banik S, et. al. Susceptibility of microorganism to selected medicinal plants in Bangladesh. Asian Pac J Trop Biomed. 2014; 4(11): 911-917. doi: 10.12980/APJTB.4.201414B362

6. Mojeremane W, Lumbile AU. A review of Pterocarpus angolensis DC. (Mukwa) an important and threatened timber species of the miombo woodlands. Research Journal of Forestry. 2016; 10(1): 8-14. doi: $10.3923 /$ rjf.2016.8.14
7. Luseba D, Elgorashi EE, Ntloedibe DT, Van Staden J. Antibacterial, anti-inflammatory and mutagenic effects of some medicinal plants used in South Africa for the treatment of wounds and retained placenta in livestock. S. Afri. J. Bot. 2007; 73(3); 378-383. doi: 10.1016/j. sajb.2007.03.003

8. Geldenhuys KJ. The many uses of Pterocarpus angolensis aka 'Kiaat' (internet). South African Forestry magazine. 2013 (cited 2015 Aug 12]. Available from: http//www.saforestryonline.co.za/...forests/the many uses_of_pterocarpus_angolensis_aka_kiaat

9. Ngonda F, Magombo Z, Mpeketula P, Mwatseteza J. Evaluation of Malawian Vernonia glabra (Steetz) Vatke leaf and Securidaca longepedunculata (Fresen) root extracts for antimicrobial activities. J Appl Pharm Sci. 2012; 2(11): 26-33. doi: 10.7324/JAPS.2012.21106

10. Kamanula JF, Sileshi GW, Belmain SR, Sola P, MvumiB, Nyirenda GKC et. al. Farmers' pest management practices and pesticidal plant use for protection of stored maize and beans in Southern Africa. Int J Pest Manag. 2011; 57(1):41-49. doi: 10.1080/09670874.2010.522264

11. Handa SS, Khanuja SPS, Longo G, Rakesh DD. Extraction Techniques for Medicinal and Aromatic Plants (internet). 2008 (cited2016 Jan 6). Available from: https://www.unido.org/sites/default/ files/2009-10/Extraction_technologies_for_medicinal_and_aromatic plants_0.pdf

12. Harborne, J.B. Photochemical Methods: A Guide to Modern Techniques of Plant Analysis. Chapman A. \& Hall, London, 1973. p. 279. doi: 10.1007/978-94-009-5921-7

13. Sofowora A.O. Medicinal Plants and Traditional Medicine in Africa. 2nd Ed .University of Ife Press; 1993.

14. European committee for Antimicrobial Susceptibilty Testing (EUCAST) of the European Society of Clinical Microbiology and Infectious Diseases (ESCMID). Determination of minimum inhibitory concentrations (MICs) of antimocrobial agents by broth dilution. 2003; 9(8): ix-xv. doi: 10.1046/j.1469-0691.2003.00790.x

15. Samie A, Housein A, Lall N, Meyer JJ. Crude extracts of, and purified compounds from, Pterocarpus angolensis, and the essential oil of Lippia javanica: their in-vitro cytotoxicities and activities against selected bacteria and Entamoeba histolytica. Ann Trop Med Parasitol. 2009; 103(5); 427-439. doi: 10.1179/136485909X435111

16. Steenkampa V, Mathivhaa E, Gouwsb MC, van Rensburga CEJ. Studies on antibacterial, antioxidant and fibroblast growth stimulation of wound healing remedies from South Africa. J Ethnopharmacol. 2004; 95(2-3): 353-357. doi:10.1016/j.jep.2004.08.020 